\title{
Nanostructured Hydroxyapatite Coating on Bioalloy Substrates: Current Status and Future Directions
}

\author{
Gladius Lewis \\ Department of Mechanical Engineering, The University of Memphis, Memphis, TN 38152, USA \\ Email: glewis@memphis.edu
}

\begin{abstract}
Several shortcomings of the alloys that are used to fabricate a number of currentgeneration biomedical implants, such as Ti-6Al-4V alloy for the femoral stem of a total hip replacement and AZ3 Mg alloy for the scaffold of a fully bioabsorbable coronary artery stent, are well-known. Examples of these shortcomings are limited bioactivity/osseointegration (in the case of Ti-based alloys) and high corrosion rate (in the case of Mg-based alloys). It is now recognized that a nanostructured hydroxyapatite (nanoHA) coating on the substrate of a bioalloy can increase bioactivity and reduce corrosion of the substrate. A large number of nanoHA deposition methods and a variety of characterization techniques/methods have been used to obtain an assortment of properties of the coating, the coated specimens, and the coating-substrate interface. Examples of these deposition methods are electrophoretic deposition and radiofrequency magnetron sputtering and some of the most frequently used characterization techniques/methods are x-ray diffraction, Fourier transform infrared spectroscopy, transmission electron microscopy, scanning electron microscopy, atomic force microscopy, immersion tests in a biosimulating solution at $37{ }^{\circ} \mathrm{C}$, and culturing in cells extracted from humans. Among the properties obtained are the morphology, thickness, size of the nanoHA; degree of crystallinity of the coating; and the adhesive strength and corrosion rate in an aqueous biosimulating solution at $37^{\circ} \mathrm{C}$. The present work is a comprehensive review of the very large body of literature in this field, with the focal topics being essential steps in a deposition method, discussion of the influence of deposition method variables on myriad coating properties (for a given deposition method), and identification of the shortcomings of the literature, and, hence, outlines of ten suggested directions for future research.
\end{abstract}

Keywords: Nanostructured hydroxyapatite (nanoHA); nanoHA coating; nanoHA coating deposition methods.

\section{Introduction}

Desirable properties for a coating on the surface of any biomedical implant include biocompatibility, nontoxicity, high resorption rate, high homogeneity, low porosity, adequate mechanical strength (in particular, high adhesive strength), and ease of deposition on a variety of implant shapes in a conformal manner [1]. In addition, for coatings on orthopaedic implants, such as the femoral stem of a total hip joint replacement (THJR), the coating should be osteoconductive, be osteoinductive, facilitate osseointegration, have excellent facilitation of bone-forming-cell functions (high osteoblast density), promote bone cell adhesion and proliferation, and promote bone mineralization [2-5]. Additionally, the coating should display excellent resistance to biofilm formation, which is adhesion of microorganisms, such as Staphylococcus aureus, that are known to be associated with infection of total joint replacements (TJRs) [6]. In a number of TRJs, prosthetic joint infection, via biofilm formation, is known to be involved in the cascade of events that culminates in their loosening, necessitating their revision [6]. Revision of a TJR is both very painful to the patient and expensive to a healthcare system [7]. For example, in the United States, about 25\% of total knee replacements (TKJRs) are revised and the total direct cost of a total THJR is $\sim \$ 70,000$ [8]. In TJRs, the ineffectiveness of antibiotic therapy (in the form of a prophylaxis or anchoring the replacement in an antibiotic-loaded acrylic bone cement bed) against biofilm formation is well-known [6]. For a coating on the scaffold of a bioabsorbable metallic coronary artery stent, there are at least two additional desirable coating properties. First, the 
coating should promote endothelial adhesion and proliferation, facilitate reduction of adhesion of platelets, and mitigate against in-segment restenosis (ISR) and in-stent thrombosis (IST) [9]. Second, the coating should provide appropriate corrosion resistance; that is, the corrosion rate should not be too low (or else, it takes too long for the stent to be absorbed in vivo) or too high because this translates to fast resorption in vivo, which is undesirable because it can, among other things, result in vascular elastic recoil and large lumen loss, which, it has been postulated, are influential factors in the development of ISR and IST [10].

Nanostructured hydroxyapatite (hereafter, "NanoHA"), that is, HA that has a fully crystalline phase at the nanoscale, possesses many of the desirable coating properties highlighted above as well as controlled pore size and high surface roughness, with the latter property being known to be directly associated with high potential for osseointegration of an orthopaedic implant [11-14]. Thus, method for depositing a nanoHA coating on metallic biomedical implants and the characterization of the coating, the coating-bioalloy substrate interface, and the coating-bioalloy substrate-electrolyte system is a very active field of research, spawning a large body of literature. However, to the best of the authors' knowledge, there are no comprehensive reviews of this body of literature; as such, the purpose of the present work was to perform such a review, subject to one caveat. This is that the review is limited to deposition of an unmodified nanoHA coating on unmodified bioalloy substrates. In other words, the following aspects are not considered: deposition of modified nanoHA coating, such as fluoridated HA [15] or nanoHA-based composites (for example, nanoHA/poly(lactic acid-co-glycolic acid) composite [16]); and deposition of an unmodified nanoHA coating on a substrate on which there is an intermediate coating, such as a $\mathrm{MgF}_{2}$ conversion coating on an AZ91 $\mathrm{Mg}$ alloy substrate [17], micro-arc oxidation coating on ZK60 Mg alloy substrate [18], plasma electrolyte oxidation film on AZ31 alloy substrate [19], polydopamine coating on AZ31 substrate [20], poly-l-lactic acid coating on cast WE43 Mg alloy [21], and titania nanotube layer on a Ti alloy [22].

The remainder of the present review is organized into four sections. In recognition that different methods have been used to synthesize nanophase HA powders that are used in the subsequent coating deposition method, the first section, Nanosphase Hydroxyapatite, is devoted to these methods and the properties of the powders. There are two focal aspects in the second section, Coating Deposition and Characterization Methods. The first involves steps used in and key process variables of each of the popular deposition methods, such as electrophoretic deposition [15,17,18,23-28] and sol-gel [29,30]; the less popular deposition methods, such as aerosol deposition [31] and radiofrequency magnetron sputtering [32]; and proprietary deposition methods, such as a patented "transonic particle acceleration deposition process" [1]. The second focal aspect involves expositions on the influence of process variables on a large collection of properties of the coating and of the coating-bioalloy substrate system, for a given coating deposition method. In the third section, Directions for Future Research, ten suggested directions for future research studies, aimed at addressing shortcomings of the extant literature, are offered. The fourth section, Summary, contains succinct summaries of the some of the key points made in the review.

\section{$2 \quad$ Nanophase Hydroxyapatite Powder}

A vast number of methods have been used to synthesize nanoHA powder and there are comprehensive reviews of these methods $[11,12,33]$. As such, only very brief summaries of four widely-used methods for synthesizing nanoHA powder used specifically in coating bioalloy substrates are given here.

One of these methods is metathesis [34,35], with the reaction involved being $10 \mathrm{Ca}\left(\mathrm{NO}_{3}\right)_{2}+6$ $\left(\mathrm{NH}_{4}\right)_{2} \mathrm{HPO}_{4}+8 \mathrm{NH}_{4} \mathrm{OH} \rightarrow \mathrm{Ca}_{10}\left(\mathrm{PO}_{4}\right)_{6}(\mathrm{OH})_{2}+6 \mathrm{H}_{2} \mathrm{O}+20 \mathrm{NH}_{4} \mathrm{NO}_{3}$.

The second is a sol-gel method. Typically, a Ca precursor (such as $\left.17 \mathrm{mMol}-2 \mathrm{M} \mathrm{Ca}\left(\mathrm{NO}_{3}\right)_{2} \cdot 4 \mathrm{H}_{2} \mathrm{O}\right)$ and a phosphorus precursor (such as $0.5 \mathrm{mM}-2 \mathrm{M} \mathrm{P}_{2} \mathrm{O}_{5}$ ) are dissolved separately in ethanol and then the Ca precursor is added drop-wise to the $\mathrm{P}$ precursor, yielding a final solution with $\mathrm{Ca} / \mathrm{P}$ molar ratio of 1.67 , which is then stirred in a closed beaker (at room temperature at, typically, $400 \mathrm{rev} \mathrm{min}^{-1}$, for $5 \mathrm{~h}$ ) until it gels $[27,36]$. Then, the gel is aged at room temperature for between $4 \mathrm{~h}$ and $72 \mathrm{~h}$, after which it is dried at $60^{\circ} \mathrm{C}$ for $24 \mathrm{~h}$, and then sintered (from $60^{\circ} \mathrm{C}$ to $600^{\circ} \mathrm{C}$ at $5^{\circ} \mathrm{C} \mathrm{min}^{-1}$ ) $[27,36]$.

The third method is wet chemical synthesis or precipitation. There are many variants of the steps that have used for this method, with five popular ones being summarized here. One involved using $\left.\mathrm{Ca}\left(\mathrm{NO}_{3}\right)_{2} \cdot 4 \mathrm{H}_{2} \mathrm{O}\right), \mathrm{KH}_{2} \mathrm{PO}_{4}$, distilled water, ammonia, and acetone, with a stirring time of $1 \mathrm{~h}$, aging time 
of $24 \mathrm{~h}$, and, finally, filtering and sintering at $900^{\circ} \mathrm{C}$ [37]. Another involved using $\mathrm{Ca}(\mathrm{OH})_{2}$ solution, $\mathrm{H}_{3} \mathrm{PO}_{4}$ solution, adjusting the $\mathrm{pH}$ of the mixture of solutions to alkaline level, stirring (at $60 \mathrm{rev} \mathrm{min}^{-1}$ for 16-24 h), centrifugation of the precipitate (at $6000 \mathrm{rev} \min ^{-1}$ for $0.5 \mathrm{~h}$ ), aging for $7 \mathrm{~d}$, washing in distilled water at least three times or in boiling water, and drying in air, after which the resulting powder was calcined (at $700^{\circ} \mathrm{C}$ for $0.5 \mathrm{~h}$ ) [38]. For the third variant, $\mathrm{Ca}\left(\mathrm{NO}_{3}\right)_{2} \cdot 4 \mathrm{H}_{2} \mathrm{O},\left(\mathrm{NH}_{4}\right)_{2} \mathrm{HPO}_{4}$, and ammonia solution were mixed and then the mixture was heated to $80{ }^{\circ} \mathrm{C}$, vigorously stirred for $1 \mathrm{~h}$, aged at room temperature for $24 \mathrm{~h}$; the suspension was washed thoroughly; and, then, the resulting gel was

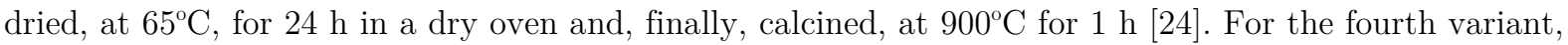
concentrated $\mathrm{NH}_{4}(\mathrm{OH})_{2}$ was added to vigorously stirred water, $\mathrm{pH}=10$, and then $\mathrm{NH}_{4} \mathrm{PO}_{3}$ and $\mathrm{Ca}\left(\mathrm{NO}_{3}\right)_{2}$ were added drop-wise while stirring for $10 \mathrm{~min}$ at room temperature and, then, the HA precipitate was placed in a Teflon liner that was sealed tightly in an autoclave and processed hydrothermally, at $200^{\circ} \mathrm{C}$ for $20 \mathrm{~h}[39,40]$. The fifth variant is a modification of the fourth one, with the modification involving spray-drying the HA precipitate at $120 \pm 5^{\circ} \mathrm{C}$ [41].

The fourth method is a hydrothermal method, in which microcrystalline HA is precipitated for 10 min at room temperature, after which some of supernatant is removed by centrifuging once to reduce the suspension by $75 \%$, and then the concentrated HA-precipitated aqueous solution is placed on a tightlysealed Teflon ${ }^{\circledR}$ liner that is in an autoclave and, finally, processed hydrothermally at $200^{\circ} \mathrm{C}$ for $20 \mathrm{~h}[39]$. After that, the HA particles are rinsed with distilled water twice and dried, in an oven that is heated at $80^{\circ} \mathrm{C}$, for $12 \mathrm{~h}[39]$.

A summary of comparison of some characteristics of nanoHA powders prepared using some of these synthesis methods is given in Table 1 .

Table 1. Comparison of some characteristics of nanophase HA powder prepared using three preparation methods

\begin{tabular}{llll}
\hline \multicolumn{1}{c}{ Characteristic } & \multicolumn{2}{c}{ Preparation method } \\
\cline { 2 - 4 } & Sol-gel & $\begin{array}{l}\text { Wet chemical } \\
\text { synthesis }\end{array}$ & Hydrothermal \\
\hline $\begin{array}{l}\text { Ca/P molar ratio } \\
\text { Mean degree of crystallinity (\%) }\end{array}$ & $45-57$ & 1.71 & 1.61 \\
$\begin{array}{l}\text { Particle size parameters } \\
\quad \text {-Mean (nm) }\end{array}$ & 31 & & 6000 \\
$\quad$-Standard deviation (nm) & 2 & $20-30$ & \\
$\quad$-Range (nm) & $10-65$ & & $31 ; 43$ \\
$\begin{array}{l}\text { Equivalent spherical crystallite } \\
\text { diameter (nm) }\end{array}$ & $18-68$ & 182 & Polygonal \\
$\begin{array}{l}\text { Mean agglomerate size (nm) } \\
\text { Particle shape }\end{array}$ & Ellipse-shaped & & \\
\hline
\end{tabular}

\section{$3 \quad$ Coating Deposition and Characterization Methods}

\subsection{Established Deposition Methods}

\subsubsection{Electrophoretic deposition}

Conventional electrophoretic deposition (EPD) is a two-step process. The first step involves preparation of a suspension of nanoHA particles (typical mean particle size and range of particle sizes: $160 \mathrm{~nm}$ and 35-550 nm, respectively) alone [27] or in combination with carbon black powder (typical mean particle size and range of particle sizes: $360 \mathrm{~nm}$ and 120-960 nm, respectively) (the powder serves as the sacrificial template) [25] in a suitable liquid, such as isopropanol [25], methanol [27], acetic anhydride [42], or ethanol [24,43]. After that, the suspension is magnetically stirred for, typically, $24 \mathrm{~h}$, and ultrasonically-dispersed [25-27], and then rested for, typically, $1 \mathrm{~h}$ (to allow sedimentation of the nanoHA particles, when only these particles are used [27]). In the second step, the suspension is placed in a cell, after which a bioalloy plate (working electrode; cathode) and a counter electrode (anode: a smaller plate of the same bioalloy [25] or another one [26,27]) are mounted in the cell. Then, a voltage is 
applied to the cell, causing the positively-charged nanoHA particles to migrate to and, ultimately, deposit on the working electrode, forming a dense coating on it [25-27].

Prior to characterization, the coated working electrode is subjected to post-treatment. Features of four of widely-used methods used for this purpose are now outlined. One, the coated specimen is dried, in

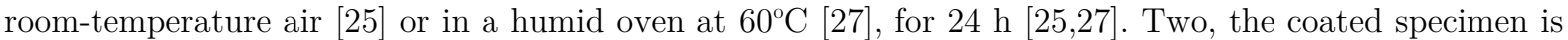
dried and then sintered (room temperature to $480^{\circ} \mathrm{C}$ at $10^{\circ} \mathrm{C} \min ^{-1}$; then, $480^{\circ} \mathrm{C}$ to $650^{\circ} \mathrm{C}$ at $1^{\circ} \mathrm{C} \min ^{-1}$; held at $650^{\circ} \mathrm{C}$ for $0.5 \mathrm{~h}$; then, $650^{\circ} \mathrm{C}$ to $700^{\circ} \mathrm{C}$ at $5^{\circ} \mathrm{C} \mathrm{min}^{-1}$; and, finally, at $700^{\circ} \mathrm{C}$ for $1 \mathrm{~h}$ ) [25]. Three, the

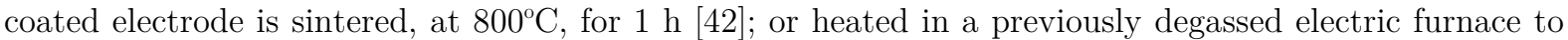
$800^{\circ} \mathrm{C}$, then heated in argon to $1000^{\circ} \mathrm{C}$ at $10^{\circ} \mathrm{C} \mathrm{min}-1$, held at $1000^{\circ} \mathrm{C}$ for $1 \mathrm{~h}$, slowly cooled in the furnace, and then removed ("Ar sintered" set) [43]; or heated in a previously degassed electric furnace to $800^{\circ} \mathrm{C}$ and then heated in vacuum to $1040^{\circ} \mathrm{C}$ at $10^{\circ} \mathrm{C} \mathrm{min}{ }^{-1}$, and then held at $1040^{\circ} \mathrm{C}$ for $1 \mathrm{~h}$, slowly cooled in the furnace, and then removed ("vacuum sintered" set) [43]. Four, the green coating is dried in air in room temperature for $24 \mathrm{~h}$ and, then, sintered in an argon-purged atmosphere at $900^{\circ} \mathrm{C}$ at $1.7^{\circ} \mathrm{C} \mathrm{min}{ }^{-1}$ with a dwell time of $1.5 \mathrm{~h}$ [24].

On 316L stainless steel substrate, the variation of the deposition current density $\left(i_{d}\right)$ with deposition time $\left(\mathrm{t}_{\mathrm{d}}\right)(0-360 \mathrm{~s})$ is influenced by the concentration of the nanoHA particles in the suspension $\left(\mathrm{C}_{\mathrm{HA}}\right)$ $(10$ or $20 \mathrm{~g} / \mathrm{L})$, the concentration of the carbon black powder in the suspension $\left(\mathrm{C}_{\mathrm{CB}}\right)(0,2.5,5.0,10.0$, or $20.0 \mathrm{~g} / \mathrm{L})$, and the voltage used in the deposition $\left(\mathrm{V}_{\mathrm{ap}}\right)(60$ or $200 \mathrm{~V})$ in a complex manner. For example, with $\mathrm{C}_{\mathrm{HA}}, \mathrm{C}_{\mathrm{CB}}$, and $\mathrm{V}_{\mathrm{ap}}=10 \mathrm{~g} / \mathrm{L}, 2.5 \mathrm{~g} / \mathrm{L}$, and $200 \mathrm{~V}$, respectively, $\mathrm{i}_{\mathrm{d}}$ dropped continuously and markedly with increase in $t_{d}$; with $C_{H A}, C_{C B}$, and $V_{a p}=20 \mathrm{~g} / \mathrm{L}, 10 \mathrm{~g} / \mathrm{L}$, and $200 \mathrm{~V}$, respectively, $i_{d}$ increased continuously and less markedly with increase in $t_{d}$; and, with $C_{\mathrm{HA}}, \mathrm{C}_{\mathrm{CB}}$, and $\mathrm{V}_{\mathrm{ap}}=20 \mathrm{~g} / \mathrm{L}, 20$ $\mathrm{g} / \mathrm{L}$, and $200 \mathrm{~V}$, respectively, $i_{d}$ increased very sharply with increase in $t_{d}$ after which $i_{d}$ was essentially invariant with increase in $t_{d}$ up to $360 \mathrm{~s}$ [25]. For a given combination of $\mathrm{C}_{\mathrm{HA}}(10$ or $20 \mathrm{~g} / \mathrm{L}), \mathrm{V}_{\text {ap }}(60 \mathrm{or}$ $200 \mathrm{~V})$, and $\mathrm{t}_{\mathrm{d}}(15-360 \mathrm{~s})$, the wet density of the deposit did not increase monotonically with increase in $\mathrm{C}_{\mathrm{CB}}(0,2.5,5.0 \mathrm{~g} / \mathrm{L})$ when $\mathrm{V}_{\mathrm{ap}}=60$ or $200 \mathrm{~V}$ or with increase in $\mathrm{C}_{\mathrm{CB}}(0,5,10 \mathrm{~g} / \mathrm{L})$ when $\mathrm{V}_{\mathrm{ap}}=60$ or $200 \mathrm{~V}$. Rather, the densest coating was obtained when the intermediate value of $\mathrm{C}_{\mathrm{CB}}$ was used; thus, with $\mathrm{C}_{\mathrm{HA}}=10 \mathrm{~g} / \mathrm{L}$, it was obtained when $\mathrm{C}_{\mathrm{CB}}=2.5 \mathrm{~g} / \mathrm{L}$, whereas, with $\mathrm{C}_{\mathrm{HA}}=20 \mathrm{~g} / \mathrm{L}$, it was obtained when $\mathrm{C}_{\mathrm{CB}}=5 \mathrm{~g} / \mathrm{L}$ [25]. Overall, the densest deposit (just slightly $<13 \mathrm{~g} \mathrm{~cm}^{-3}$ ) was obtained with $\mathrm{C}_{\mathrm{HA}}, \mathrm{C}_{\mathrm{CB}}, \mathrm{V}_{\mathrm{ap}}$, $\mathrm{i}_{\mathrm{d}}$, and $\mathrm{t}_{\mathrm{d}}$ of $20 \mathrm{~g} / \mathrm{L}, 5 \mathrm{~g} / \mathrm{l}, 200 \mathrm{~V}, 40 \mathrm{~A} \mathrm{~cm}^{-2}$, and $360 \mathrm{~s}$, respectively [25]. The influence of $\mathrm{C}_{\mathrm{HA}}, \mathrm{C}_{\mathrm{CB}}$, and $\mathrm{V}_{\text {ap }}$ on the kinetics of deposition is also complex. For example, with $\mathrm{C}_{\mathrm{HA}} / \mathrm{C}_{\mathrm{CB}}=0.50$ and $\mathrm{V}_{\text {ap }}$ was either 60 $\mathrm{V}$ or $200 \mathrm{~V}$, the increase in deposit mass per surface area of substrate $\left(\mathrm{D}_{\mathrm{md}}\right)$ with increase in $\mathrm{i}_{\mathrm{d}}$ was linear; with $\mathrm{C}_{\mathrm{HA}} / \mathrm{C}_{\mathrm{CB}}=0.25$ and $\mathrm{V}_{\mathrm{ap}}=60 \mathrm{~V}$ or $200 \mathrm{~V}$, this increase appeared to be slightly parabolic, and, with $\mathrm{C}_{\mathrm{HA}} / \mathrm{C}_{\mathrm{CB}}=1.00$ and $\mathrm{V}_{\mathrm{ap}}=60$ or $200 \mathrm{~V}, \mathrm{D}_{\text {md }}$ fluctuated with increase in $\mathrm{i}_{\mathrm{d}}$ in a hysteresis-like manner [25].

After 3 or 5 days of exposure of Ti-6Al-4V specimens to osteoblasts cultured in Dulbecco's Modified Eagle Medium (DMEM) supplemented with $1 \%$ fetal bovine serum and $1 \%$ penicillin, the results of a $4-$ hour 3-(4,5-dimethylthiazol-2-yl)-2,5-diphenyltetrazolium bromide (MTT) osteoblast assay (seeding density $=35$ cells $\mathrm{cm}^{-2}$ ) showed significantly high cell viability (higher osteoblast density) for specimens covered with a nanoHA coating deposited using EPD compared to uncoated specimens, demonstrating significantly easier formation of a mineralized matrix by osteoblasts when exposed to the former specimens [26]. Also, results of a bacterial assay using $S$. aureus showed that, after $8 \mathrm{~h}$ of culture, there was significantly decreased bacteria colonization (significantly fewer colony-forming units) on the specimens that were nanoHA-coated compared to uncoated specimens, a trend that is consistent with the significantly greater hydrophilicity (greater surface area and exposure of the coating on the substrate) of the former specimens [26].

On AZ91 (Mg-9Al-1Zn alloy) specimens, the coating is practically crack-free, homogenous, and rough, with the last-mentioned characteristic being good because rough surfaces are known to confer excellent performance (high stimulation of the adhesion, growth, and proliferation of osteoblasts and improved osseointegration) [44,45]. Results of corrosion tests (potentiodynamic polarization of AZ91 specimens immersed in acellular simulated body fluid (a-SBF-2 solution) at $37 \pm 1^{\circ} \mathrm{C}$ ) found marked decrease in corrosion rate (lower corrosion current density) for coated specimens compared to uncoated ones (mean decrease of $\sim 90 \%$ ), indicating effective mediation of corrosion by the coating [27].

On a Ti substrate roughened by etching and oxidizing in a 1:1 (vol./vol.) concentrated $\mathrm{H}_{2} \mathrm{SO}_{4}$ and $30 \% \mathrm{H}_{2} \mathrm{O}_{2}$ mixture, 1) the coating was homogeneous without cracks; 2) the adhesive strength of the coating was $18 \pm 2.5 \mathrm{MPa}$, with fracture occurring at the coating-substrate interface; and 3) the coating displayed good biocompatibility and bioactivity, as illustrated by the following results: after culturing 
for $3 \mathrm{~d}$, rabbit mesenchymal stem cells (MSCs) adhered onto the coating and elongated; after 12 days, cell adhesion increased significantly and the cells covered the coating completely; and after culturing for 4 days, the MSC proliferation on the coated substrate was markedly greater (27\% increase) than on an uncoated substrate [42].

On 316 LVM stainless steel substrate, 1) coatings deposited after $30 \mathrm{~s}$ and then vacuum-sintered were thin and compact; for coatings deposited after $60 \mathrm{~s}$ and vacuum sintered, the outer layer of agglomerated clusters had cracks through which a continuous inner layer of finer and sintered particles was visible; and for coatings deposited after $30 \mathrm{~s}$ and then argon-sintered, the morphology was observable not only at the agglomerates at the surface but also over all of the visible areas [43].

On Ti-8Al-4V alloy substrates prepared using wire brushing (with a 64-mm-diameter circumferential brush having stainless steel wires, rotated at 12,000-27,000 revolutions $\mathrm{min}^{-1}$, for $45-75 \mathrm{~s}$ while a $2 \mathrm{~kg}$ force was applied vertically to the surface of the workpiece, followed by mechanical polishing and etching (WB substrate)), the adhesive strength of the coating was twice as high and the coating was half as porous as the case when the coating was deposited on an as-received (AR) substrate [24]. It was postulated that this trend is a consequence of the surface roughening and enhanced mechanical interlocking induced by the wire brushing [24]. Furthermore, the corrosion rate (in corrected SBF, in air, at $37.4{ }^{\circ} \mathrm{C}$ ) when WB-coated specimens were used was about $50 \%$ that when AR-coated specimens were used, a consequence of the significantly lower porosity of the coating on the former specimens [24].

\subsubsection{Room-temperature electrophoretic deposition (RTEPD)}

This variant of the EPD method leads to a coating that does not have an amorphous phase, has excellent bond strength, but high porosity [46]. On Ti substrate, high-temperature sintering was used as a post-treatment method to decrease the porosity of the coating but as a consequence of the large difference in the coefficients of expansion of the coating and the Ti, cracks formed in the coating [46].

On Ti alloy substrate, the adhesive strength of a RTEPD-deposited coating and the corrosion resistance it provides are 2-3 times higher and 50-100 times higher, respectively, than the corresponding values when a thermally-sprayed HA coating was used [46].

\subsubsection{Sol-gel deposition}

This is a two-step process, with the salient features in each step now given. In the first step, the final sol-gel solution is prepared and stirred, as described in Section 2 above, after which one of the two process paths is taken. In the first, either an electric coat dipper or a belt-and-pulley assembly is used to vertically immerse a bioalloy specimen (usually, abraded and cleaned rectangular workpiece) into the solution and then withdrawn at, say, $6 \mathrm{~mm} \mathrm{~min}^{-1}$ or $50 \mathrm{~mm} \mathrm{~min}^{-1}[27,36]$. Alternatively, the specimen is dipped into the solution and rotated at, say, $2000 \mathrm{rev} \mathrm{min}^{-1}$, and then withdrawn [30]. In the second step, the coated specimen is aged at room temperature for $24 \mathrm{~h}$, dried in a humid oven at, typically, $60^{\circ} \mathrm{C}$ or $80^{\circ} \mathrm{C}$ for $24 \mathrm{~h}$ and, then, calcined/sintered to, say, between $400^{\circ} \mathrm{C}$ and $700^{\circ} \mathrm{C}$, at a heating rate of $1^{\circ} \mathrm{C}$ $\min ^{-1}[27,36]$. Alternatively, the coated specimen is placed in an air oven and held there at $150^{\circ} \mathrm{C}$ for 10 min, and then, sintered at $300-900^{\circ} \mathrm{C}[30]$.

On die-cast AZ91 specimens, the coating 1) has a thickness of $6.3 \pm 1.1 \underline{\mu m}$ [29]; 2) has poor crystallinity (index $=45 \%$ ) [29], which was attributed to the low curing temperature that was used $\left(400^{\circ} \mathrm{C}\right)$ so as to not adversely affect the surface integrity of the substrate and decrease its tendency to react with oxygen $[47,48]$; and 3) is practically crack-free, homogenous, free of any delamination and/or gaps, and relatively smooth $[27,29]$. The last-mentioned characteristic indicates that some aspects of the performance of the coated specimen may be sub-optimal, as evidenced by low stimulation of the adhesion, growth, and proliferation of osteoblasts and low osseointegration of the coated specimens $[44,45]$.

Results of an adhesion test (per ASTM D454-02) performed using a commercially-available adhesion tester found that the bonding strength of the coating to a die-cast AZ91 substrate was $4.2 \pm 0.3 \mathrm{MPa}$ and that there were cohesive and adhesive modes in the failure surface of the coating [29].

Results of corrosion tests (potentiodynamic polarization of die-cast AZ91 specimens immersed in cSBF2 solution at $\left.37 \pm 1^{\circ} \mathrm{C}[27,29]\right)$ found marked decrease in corrosion rate for coated specimens compared to uncoated ones (mean decrease of $\sim 87 \%$ ), indicating that the coating provided an effective barrier against the electrolyte $[27,29]$. In another corrosion test, electrochemical impedance spectroscopy (EIS) measurements were made on the two above-mentioned systems (uncoated specimen-electrolyte and coated specimen-electrolyte systems). The results were presented in the form of a Nyquist plot (imaginary part of the impedance of the system versus real part of the impedance of the system, as a 
function of the frequency (f) of the applied a. c. voltage (10 $\mathrm{mV}$ rms peak-to-peak)) and a Bode plot (magnitude of the impedance of the system versus f) [29]. The Nyquist plots were qualitatively the same for the two systems, with low-frequency loops seen that are attributable to pitting and/or release of oxidation products, such as $\mathrm{Mg}$ ions and magnesium hydroxide [29]. Relevant phenomena in these events include involvement of adsorbed intermediate species in the reduction in the cathodic reaction (reduction of hydrogen gas) and rearrangement of surface charge at the oxide/metal interface (in the case of uncoated specimen) [49]. Bode plots for an equivalent electrical circuit of each of the aforementioned two systems were calculated using a commercially-available software package and, in each case, the match with the experimental results was excellent, pointing to the plausibility of the suggested equivalent electrical circuit (EQCRT) [29] (Figure 1). In EQCRT, the CPE is, in this case, a double-layer capacitor and $\mathrm{R}_{\mathrm{ct}}$ is inversely proportional to the corrosion rate of the test specimen. The significant decrease in the corrosion rate of the coated specimen compared to the uncoated one was confirmed by the significant increase in $\mathrm{R}_{\mathrm{ct}}(\sim 220 \%)$, increase in $\mathrm{C}_{\mathrm{dl}}$ (factor of 134$)$, decrease in $\mathrm{L}(\sim 80 \%)$, and increase in $\mathrm{R}_{\mathrm{L}}(\sim 442 \%)$ [29].

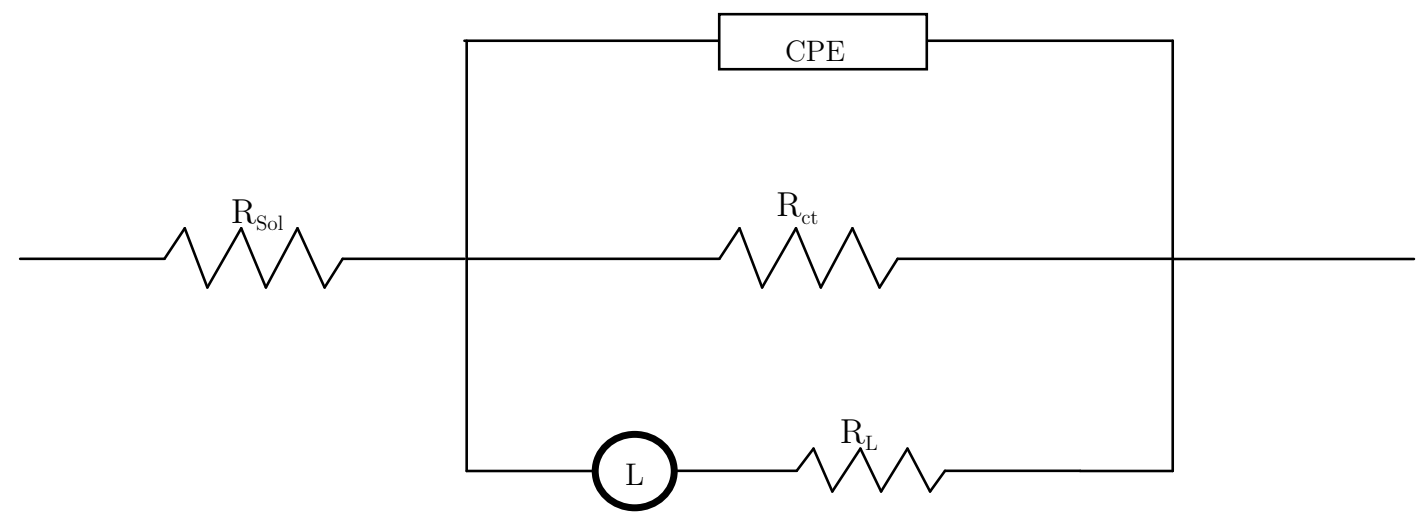

$\mathrm{R}_{\mathrm{sol}}$ : solution (electrolyte) resistance; CPE: constant-phase element;

$\mathrm{R}_{\mathrm{ct}}$ : charge transfer resistance; $\mathrm{L}$ : system inductance; $\mathrm{R}_{\mathrm{L}}$ : inductance resistance.

Figure 1. Schematic drawing of the equivalent electrical circuit for the nanoHA coating-plain AZ91 Mg alloy substrate-electrolyte (c-SBF, at $37 \pm 1^{\circ} \mathrm{C}$ ) system. (Circuit was proposed by Rojaee et al. [29] as an acceptable model for the experimental results).

On 316L stainless steel substrate, 1) the coating was uniform, amorphous, with a thickness of $1.4 \mu \mathrm{m}$ and mean Vickers hardness of $1.2 \mathrm{GPa}$; 2) EIS results, obtained after immersion of specimens in Ringer's solution, at $37^{\circ} \mathrm{C}$, for $1 \mathrm{~h}$, found $\mathrm{R}_{\mathrm{ct}}$ when a coated specimen was used was over 4 times higher (hence, corrosion rate over 4 times lower) than when an uncoated specimen was used [30]; and 3) the sintering temperature $\left(\mathrm{T}_{\mathrm{s}}\right)\left(300^{\circ} \mathrm{C} \leq \mathrm{T}_{\mathrm{s}} \leq 900^{\circ} \mathrm{C}\right)$ exerted marked influence on each of the characteristics of the coating; for example, with increase in $\mathrm{T}_{\mathrm{s}}$, the coating was more uniform and compact, coating thickness increased, and corrosion resistance and adhesive strength increased in a monotonic manner (up to $\mathrm{T}_{\mathrm{s}}$ of $800^{\circ} \mathrm{C}$ ), but, at $900^{\circ} \mathrm{C}$, there was depreciation of each of these properties) [30].

On Ti substrates, 1) increase of $\mathrm{T}_{\mathrm{s}}$ from $600^{\circ} \mathrm{C}$ to $700^{\circ} \mathrm{C}$ led to increase in the crystallinity of the coating but not of either its crystallite size or grain size, and 2) when the coating was not aged, it consisted of calcium oxide in addition to HA and, hence, delaminated easily [36].

\subsubsection{Electrostatic spray deposition}

Two variants of this method have been described. In the first variant (the NanoSpray ${ }^{\circledR}+$ microwave sintering process), a charge comprising nanoHA particles and a stream of air is fed into a powder spray gun; and, upon exit from the gun, the particles are exposed to an electrostatic field that is generated by a pointed electrode (typical voltage $=60-80 \mathrm{kV}$ ), thus, making them charged. These charged particles follow the electric field lines toward the grounded member (the bioalloy test specimen), upon which they deposit, forming the coating [14]. Finally, the coated specimen is sintered in air in a microwave furnace (typical temperature and time $=1000-1300^{\circ} \mathrm{C}$ and $5-20 \mathrm{~min}$, respectively) [14]. On both textured and 
machined Ti substrates, 1) the coating was uniform, highly crystalline, with $\mathrm{Ca} / \mathrm{P}$ ratio of $1.6 \pm 0.06$ (very close to that of natural bone), thickness of $60.0 \pm 2.1 \mu \mathrm{m}$, grain size of 50-300 nm, and excellent adhesion to the substrate; and 2) attachment of human palatal MSCs that had been cultured in Eagle's Minimum Essential Medium with 10\% fetal bovine serum was very good after 72 h exposure (85-90\%), pointing to the high potential for early osteoblast gene expression of a coated bioalloy device in vivo [14].

In the second variant (an in-house spray system), a suspension of nanoHA particles (prepared using wet chemical synthesis) in ethanol was prepared using sonication of $15 \mathrm{~min}$, after which the suspension was loaded into a syringe that was then mounted onto a syringe pump. A peristaltic pump was used to feed the suspension to a capillary tube. A voltage $(5.6 \mathrm{kV})$ was applied across the tube and the grounded bioalloy specimen (substrate), causing the suspension to be atomized. The substrate was firmly attached to an XYZ stage that was moved by a manipulator. The resulting electrospray droplets of the nanoHA were thus directed onto the substrate, with a coating deposited on it after the solvent evaporated. To ensure uniform deposition, the manipulator moved the stage in a precise manner. The final step involved washing the specimen with deionized water and, then, drying it in room-temperature air [50].

On Ti-6Al-4V substrates, the coating 1) provided a rougher surface on the substrate compared to an uncoated specimen (arithmetic mean of the departures of the roughness profile from the mean line $=$ $2.77 \mu \mathrm{m}$ and $2.34 \mu \mathrm{m}$ squared of average roughness $=3.86 \mu \mathrm{m}$ and $2.94 \mu \mathrm{m}$ for the coated and uncoated specimens, respectively); and 2) conferred substantially increased corrosion resistance (in Hank's solution, at room-temperature): the computed corrosion rate, from the results of potentiodynamic tests, in $\mathrm{g} \mathrm{h}^{-1}$, when a coated specimen was used was $3.4 \times 10^{-4}$ that when an uncoated specimen was used) [50].

\subsubsection{Electrodeposition}

Typical steps in the process are now presented. In a two-electrode system, the bioalloy specimen and a $\mathrm{Pt}$ plate serve as the working electrode and counter electrode, respectively, and the electrolyte is prepared using either $\mathrm{CaCl}_{2}, \mathrm{NaH}_{2} \mathrm{PO}_{4}, \mathrm{NaCl}$ and then the $\mathrm{pH}$ is adjusted to $6.3[51]$ or $\mathrm{Ca}\left(\mathrm{NO}_{3}\right)_{2}$ and $\mathrm{NaH}_{2} \mathrm{PO}_{4}$, and then the $\mathrm{pH}$ is adjusted to 7.4 [52]. For the deposition, two approaches have been described. In one, a commercially-available electrochemical workstation is used for the electrodeposition, using a current density (i) of $\sim 1 \mathrm{~mA} \mathrm{~cm}^{-2}$, solution temperature of $\sim 100^{\circ} \mathrm{C}$, and deposition time of $1 \mathrm{~h}$ [51]. To minimize evaporation of the solution, a three-necked flask (one each for the working electrode, counter electrode, and a reflux tube) was used as a container. At the end of the deposition, the working electrode was rinsed three times using deionized water and, then, dried in air [51]. In the other approach, the bath containing the electrolyte is agitated throughout the deposition (using an ultrasonic generator), with the operation carried out at room temperature, using i of either 10 or $15 \mathrm{~mA} \mathrm{~cm}^{-2}$, for $0.5 \mathrm{~h}$ [52].

On Ti substrate, 1) the coating has a uniform two-layer topography, with wire-like nanocrystals in the outer layer and an ordered nest-like microtopography in the inner layer; 2) HA nucleates heterogeneously and then grows preferentially in the direction of the $c$-axis; 3) it was suggested that conditions necessary for the formation of the nanoHA coating are heterogeneous formation of adequate fine nuclei on the substrate, uniform growth environment for the nuclei, elimination of secondary nucleation, and formation of a viable gas bubble template on the substrate; and 4) the coated specimen demonstrated excellent biocompatibility and bioactivity against MG63 human osteosarcoma cells, with this result attributed to the nanostructure of the coating [51].

On Ti substrate, 1) the coating comprised complete and uniform coverage of small globules of HA; 2) there was clear influence of process variables on coating properties; thus, with ultrasonic agitation and $\mathrm{i}$ of $10 \mathrm{~mA} \mathrm{~cm}{ }^{-2}$, grain size $\left(\mathrm{d}_{\mathrm{g}}\right)$, mean surface roughness $\left(\mathrm{R}_{\mathrm{a}}\right)$, and mean adhesion strength $\left(\right.$ mean $\left.\sigma_{\mathrm{A}}\right)$ were $18 \mathrm{~nm}, 0.28 \mu \mathrm{m}$, and $7.2 \mathrm{MPa}$, respectively; with ultrasonic agitation and i of $15 \mathrm{~mA} \mathrm{~cm}^{-2}, \mathrm{~d}_{\mathrm{g}}, \mathrm{R}_{\mathrm{a}}$, and mean $\sigma_{\mathrm{A}}$ were $25 \mathrm{~nm}, 0.22 \mu \mathrm{m}$, and $8.7 \mathrm{MPa}$, respectively; and without agitation and $\mathrm{i}$ of $15 \mathrm{~mA} \mathrm{~cm}^{-2}, \mathrm{~d}_{\mathrm{g}}$ was found to be $90 \mathrm{~nm} ; 3$ ) when agitation was used, the low $\sigma_{\mathrm{A}}$ is a consequence of the severe agitation conditions used; 4) after 2 days in culture in SaOS-2 (human osteoblast-like cells derived from a human osteosacorma), viability when a coated specimen $\left(\mathrm{i}=10 \mathrm{~mA} \mathrm{~cm}{ }^{-2}\right)$ was used was significantly higher than that for uncoated specimen but, with $\mathrm{i}=15 \mathrm{~mA} \mathrm{~cm}$, the difference in cell viability between coated and uncoated specimens was not significant; 5) in the same cell culture as was used for item 4) above, total protein activity (TPA) was significantly higher on a coated specimen (regardless of the level of i) compared to an uncoated specimen; 6) based on the cell viability and TPA results, the coating deposited using $10 \mathrm{~mA} \mathrm{~cm}{ }^{-2}$ was superior to that obtained using $15 \mathrm{~mA} \mathrm{~cm}^{-2}$, a consequence of the 
former's lower HA crystallite size; 7) during deposition, hydrogen gas bubbles were produced, which served as a template on which the HA crystals grow; and 8) during the early part of the deposition process (say, the first 12 minutes or so), nucleation of the HA crystals was instantaneous and there was two-dimensional growth of the coating, but, in the latter stages of deposition, the nucleation mechanism changed to progressive, with accompanying three-dimensional growth of the coating [52].

\subsubsection{Hydrothermal deposition}

The essential features of the three steps in this method, as presented in one report, are now outlined [53]. First, a buffer solution was prepared by dissolving HEPES buffering agent in $\mathrm{NaO}$ aqueous solution, followed by dissolution of $\mathrm{K}_{2} \mathrm{HPO}_{4}$ and $\mathrm{CaCl}_{2}$, and adjustment of $\mathrm{pH}$ to 7.4. Second, the bioalloy specimen was placed in a beaker, the buffer solution was poured in the beaker, and the solution was hydrothermally treated at a temperature $\left(\mathrm{T}_{\mathrm{h}}\right)$ of $80-200^{\circ} \mathrm{C}$ for a time $\left(\mathrm{t}_{\mathrm{h}}\right)$ of $5-12 \mathrm{~h}$ [53]. In the third step, the specimen was ultrasonically washed in distilled water for $5 \mathrm{~min}$ and, then, dried in air at $50^{\circ} \mathrm{C}$ for 24 $\mathrm{h}[53]$.

On a Ti-Nb alloy substrate, 1) when $\mathrm{T}_{\mathrm{h}}$ was $200^{\circ} \mathrm{C}$, a dense nanoHA layer formed on the substrate at $5 \mathrm{~h} \leq \mathrm{t}_{\mathrm{h}} \leq 12 \mathrm{~h}$; and 2) $\mathrm{TiO}_{2}$ and $\mathrm{Nb}_{2} \mathrm{O}_{5}$ formed on the surface of the substrate during the hydrothermal treatment, which, then, transformed into $\mathrm{Ti}(\mathrm{OH})_{4}$ and $\mathrm{Nb}(\mathrm{OH})_{5}$, respectively [53].

\subsection{Newer/Emerging Deposition Methods}

\subsubsection{Aerosol deposition}

There have been only a few reports of the use of this method [31,54]. The steps used in these two studies are now summarized. In the study by Dong et al. [31], commercially-available nanoHA powder was heated, in air, at $1200^{\circ} \mathrm{C}$, for $1 \mathrm{~h}$, after which the powder was ball milled, using yttria-stabilized zirconia balls, for $24 \mathrm{~h}$; and, after that, the powder was heated in air again (at $900^{\circ} \mathrm{C}$ for $1 \mathrm{~h}$ ). This yielded the final prepared powder (herein "prepared powder"), which was then used for deposition of the coating with the aid of an in-house powder spray coating equipment. The process involved pouring $\sim 50 \mathrm{~g}$ of the prepared powder into the powder chamber that was shaken throughout the coating deposition process in order to produce a fine powder particle suspension in the upper part of the chamber. Oxygen gas, flowing at $5 \times 10^{-4} \mathrm{~m}^{3} \mathrm{~s}^{-1}$, was used to move the fine powder particles from the powder chamber into the deposition chamber (which was evacuated to $0.65 \mathrm{~Pa}$ ) and to spray these particles onto the bioalloy specimen through a nozzle in the deposition chamber that has a slit-type opening. The specimen was firmly fixed to a steel plate that itself was attached to a motored X-Y stage. Uniform coating was ensured by moving the substrate at a fixed rate $\left(1 \mathrm{~mm} \mathrm{~s}^{-1}\right)$ during deposition of the coating. The final step was to clean the coated specimen in an ultrasonic bath and then wash it in ethanol [31]. An optional step is to heat the coated specimen in air, at, say, 400 or $500^{\circ} \mathrm{C}$ for, say, $1 \mathrm{~h}$.

On Ti substrate, 1) before heat treatment, the coating comprised HA crystallites ( $\operatorname{size}=16.2 \pm 5.5$ $\mathrm{nm}$ ) and fine amorphous regions, whereas, after heat treatment, the size of the crystallites increased and the amorphous region disappeared; 2) the coating was dense (density $=3108 \mathrm{~kg} \mathrm{~m}^{-3}$, which is $98.5 \%$ of theoretical density), $1 \mathrm{~mm}$ thick, and without any observable pores or cracks or delamination; 3) the tensile adhesion strength of the coating (per ISO 13779) [55] was 30.5 $\pm 1.2 \mathrm{MPa}$, which is about twice the minimum recommended level for HA-coated metal specimens (15 MPa [55]; 4) proliferation of MT3C3-E1 pre-osteoblast cells (cultured in a-minimum essential medium and supplemented with $10 \%$ heat-inactivated fetal bovine serum, L-glutamine, penicillin, and streptomycinin in a humidified atmosphere $\left(96 \%\right.$ air $\left.+5 \% \mathrm{CO}_{2}\right)$, at $37^{\circ} \mathrm{C}$ for 5 days) ) on coated specimens was significantly greater than on uncoated specimens, a trend that was also seen in the alkaline phosphatase (ALP) activity results. All of the aforementioned results underscore the superior biocompatibility of the coated specimens [31].

In the second report [54], the first step in coating a bioalloy substrate was to heat a commerciallyavailable $\mathrm{HA}$ powder, in air, at $1500^{\circ} \mathrm{C}$, for $3 \mathrm{~h}$. After that, the powder was poured into a powder chamber and the specimen was placed in the chamber, which was then evacuated and air (the carrier gas) flowed into the chamber (at $30 \mathrm{~L} \mathrm{~min}^{-1}$ ). Thus, the HA particles and the air were mixed in the chamber and then the mixture was ejected through a nozzle in the chamber onto the substrate, which was positioned on a motorized X-Y stage. The coating was formed by the collision of the accelerated HA particles + air mixture with the substrate. For post-treatment, the coated substrate was heat treated 
using hydrothermal annealing; that is, heated in an autoclave that contained distilled water, at 150$190^{\circ} \mathrm{C}$, for $29 \mathrm{~h}[54]$.

On Ti substrate, 1) the composition of the nanoHA powder and the coating remained unchanged during the coating process; 2) the as-deposited coating was rough, with a sparse network-type microstructure, but the coating-substrate interface was continuous; however, after a hydrothermal treatment, the coating was free of cracks and its morphology was similar to that of an as-deposited coating; 3) a specimen with a hydrothermally-treated coating displayed higher bioactivity (in SBF, at $36.5^{\circ} \mathrm{C}$, for $7 \mathrm{~d}$ ) than one with as-deposited coating this was attributed to the earlier precipitation of apatite crystals on the former coating, a consequence of the higher population of $\mathrm{OH}^{-}$groups with increased degree of crystallinity as well as their smaller crystallite size; and 4) a specimen with hydrothermally-treated coating displayed enhanced biological cellular response (in MC3T3-E1 preosteoblast cells assay) than one with an as-deposited coating, attributed to the higher degree of crystallinity of the former coating [54].

\subsubsection{Pulse electrodeposition}

Only a few reports of the use of this method have appeared [56,57]. Three steps were used in the deposition and key features in each step are now given. In the first step, the electrolyte was prepared, this involving mixing a solution of $\mathrm{Ca}\left(\mathrm{NO}_{3}\right)_{2}, \mathrm{NH}_{4} \mathrm{H}_{2} \mathrm{PO}_{4}$, and $\mathrm{H}_{2} \mathrm{O}_{2}$, adjusting the $\mathrm{pH}$ of the solution to 4.5 , and, then, stirring the solution (at $400 \mathrm{rev} \mathrm{min}^{-1}$ ) to obtain a uniform solution ("prepared solution"). In the second step, the prepared solution was placed in a cell together with the bioalloy specimen (cathode), a platinum electrode (anode), and a reference electrode (such as the saturated calomel electrode). In the third step, a voltage generator was used to apply a pulse potential $\left(\mathrm{V}_{\mathrm{pp}}\right)$ to the cell and potentiostatic deposition of the coating on the substrate was achieved. Typical $\mathrm{V}_{\mathrm{pp}}=-3 \mathrm{~V}$ and typical duty cycle $=0.2$. Duty cycle is defined as the ratio, $t_{\text {on }} /\left(t_{\text {on }}+t_{\text {off }}\right)$, where $t_{\text {on }}$ is the time during which $V_{p p}$ is applied and $t_{\text {off }}$ is the time during which there is no current or applied potential and the potential of the direct mode is set to $\mathrm{V}_{\mathrm{pp}}[56,57]$.

On AZ31 Mg (Mg-2.8Al-0.9Zn alloy) substrate, 1) the coating was uniform, intertwined, and compact, with a crystallinity index of $94 \%$; 2) the coating significantly reduced the degradation rate of the specimen (at any immersion time of the specimens in SBF solution, each of two corrosion measures using coated specimen was half of that when a uncoated specimen was used). These measures directly determined degradation rate and $\mathrm{Mg}^{2+}$ concentration in the solution; 3) the coating provided significantly better resistance to corrosion of the specimen, in SBF solution at $37 \pm 1^{\circ} \mathrm{C}$, compared to the case when the substrate was not coated, as evidenced by the results of two other corrosion tests: significantly lower corrosion current $\left(\mathrm{i}_{\text {corr }}\right)$ ( 93\% drop), as determined from potentiodynamic tests, and significantly lower amount of hydrogen evolved (10-fold decrease). It was pointed out that the latter result suggests that nucleation of bones would be facilitated when a nanoHA coated implant is used [58]; 4) EIS results showed (i) a low-frequency inductive loop in the Nyquist plot, (ii) that an applicable model for the coating-substrate-electrolyte system is describable using the equivalent electrical circuit, EQCRT (Figure 1), and (iii) the superior corrosion performance of the coated specimen is reiterated by a significant increase in $\mathrm{R}_{\mathrm{ct}}$ (by a factor of $\sim 6$ ) and a significant decrease in $\mathrm{C}_{\mathrm{dl}}$ (by $\sim 80 \%$ ) compared to the corresponding values when an uncoated specimen was used $[56,57]$.

Furthermore, on AZ31 Mg alloy specimens, clear differences were found in both the coating itself and the performance of the coated specimen when pulsed voltage was used in depositing the coating ("PVcoated specimens") compared to when a constant voltage was used ("CV-coated specimens") [57]. For example, 1) the mean adhesion strength of PV-coated and CV-coated coatings were 16.5 and $11.5 \mathrm{MPa}$, respectively, consistent with the fact that the former and latter coatings are compact and porous, respectively; 2) mean $R_{\mathrm{ct}}$ for uncoated, CV-coated, and PV-coated specimens were 40, 98, and $295 \Omega . \mathrm{cm}^{2}$, respectively, showing that the lowest corrosion rate was obtained with PV-coated specimens; and 3) the degradation rate in SBF of PV-coated specimens is about half that of both uncoated and CV-coated specimens. Each of these three sets of results is explained by the fact that the surfaces of the uncoated specimen, the CV-prepared nanoHA coating, and the PV-prepared nanoHA coating are porous, porous, and compact, respectively [56,57].

\subsubsection{Radiofrequency magnetron sputtering}

In one report, an apparatus that included a radiofrequency $(\mathrm{RF})$ magnetron source was used to deposit the coating, with typical conditions being $\mathrm{RF}$ power level=500W and medium being pure Ar atmosphere [32]. On AZ31 Mg alloy substrate, 1) the coating was homogeneous and had regular grain-like 
morphology; 2) the coating was homogeneously deposited on the substrate; 3) both $\mathrm{d}_{\mathrm{g}}$ and $\mathrm{Z}$ range of surface roughness $\left(\Delta \mathrm{R}_{\mathrm{r}}\right)$ of the coating increased with increase in coating thickness (l); thus, with $1=$ $700 \mathrm{~nm}, \mathrm{~d}_{\mathrm{g}}$ and $\Delta \mathrm{R}_{\mathrm{r}}$ were $85 \pm 30 \mathrm{~nm}$ and $42.9 \mathrm{~nm}$, respectively, while, with $\mathrm{L}=1500 \mathrm{~nm}$, the corresponding values were $250 \pm 55 \mathrm{~nm}$, and $90.8 \mathrm{~nm}$, respectively; 4) regardless of the thickness of the coating, it conferred an increase in contact angle (compared to the uncoated substrate), in deionized water at $20^{\circ} \mathrm{C}$, a consequence of the hierarchical organization of the coating; 5) potentiodynamic corrosion tests, in 3.5 wt./wt.\% $\mathrm{NaCl}$ solution at $37^{\circ} \mathrm{C}$, showed the corrosion rate of a coated specimen to be significantly lower than that of the uncoated specimen (drops of $\sim 76 \%$ and $\sim 93 \%$ when coating thickness was $700 \mathrm{~nm}$ and $1500 \mathrm{~nm}$, respectively) [32].

\subsubsection{Electrohydrodynamic spray deposition (EHDSD)}

In one report of the use of this method, a HA suspension was sprayed onto the target specimen for $30 \mathrm{~s}$, followed by a heat treatment [38]. More details are now provided. A needle connected to a power supply and a syringe attached to a pump were used to control the flow rate of the nanoHA suspension. The voltage applied to the needle $\left(V_{n}\right)$ and flow rate of the suspension $\left(M_{s}\right)$ were adjusted to obtain the conejet mode of electrohydrodynamic spraying (typically, $\mathrm{V}_{\mathrm{n}}$ and $\mathrm{M}_{\mathrm{s}}$ were $4.8 \mathrm{kV}$ and $18 \mathrm{~L} \mathrm{~min}^{-1}$, respectively), with the spray directed onto the bioalloy substrate. After deposition of the coating, the specimen was heated, in air, from room temperature to $900^{\circ} \mathrm{C}$, at $2^{\circ} \mathrm{C} \mathrm{min}^{-1}$, held at this temperature for $2 \mathrm{~h}$, and, then, cooled to room temperature [38].

On Ti substrate, 1) the thickness of the coating, which was free of cracks and nanoHA particle agglomeration, more than doubled from an initial value of $2.1 \pm 0.7 \mathrm{~mm}$, when spray time was increased from $30 \mathrm{~s}$ to $120 \mathrm{~s}$; and 2) the coating showed bioactivity (in distilled water, at $37^{\circ} \mathrm{C}$, for 7 days), with its surface morphology changing, after 5 days' immersion, from rod-like nanoHA particles to a cauliflower-like (spheroidal) structure that is similar to that of bone-like apatite formed in vitro [38].

\subsubsection{Liquid precursor plasma spraying (LPPS)}

In this process, the feedstock (HA liquid precursor) is atomized into a mist and injected into a plasma jet through an atomizing nozzle. The nanoHA coating is deposited using a direct-current plasma torch attached to a thermal spraying robotic arm [59].

On Ti-6Al-4V substrate, the coating 1) consisted primarily of the HA phase with very small amounts of $\beta$-tricalcium phosphate and $\mathrm{CaO}$ phases, 2) was carbonated; 3) had many small (5-20 $\mu \mathrm{m})$ splats, 4) had nano-scale (20-50 nm)HA particles in certain regions, 5) had a crystallite size and thickness of $\sim 56$ $\mathrm{nm}$ and $\sim 100 \mu \mathrm{m}$, respectively, with these nano-structured features postulated to be due to limited grain growth in the very short deposition time; and 6) showed the presence of the $\mathrm{OH}^{-}$group (which suggests that the coating had good structural integrity) [59].

\subsection{Proprietary Deposition Methods}

When the IonTite ${ }^{\mathrm{FM}}$ method (Spire Biomedical, Inc., Bedford, MA, USA), which is described as a lowtemperature process, was used to deposit nanoHA coating on $\mathrm{Ti}$ substrate, 1) adhesion of human osteoblast-like cells (ATTC, CRL-11372) was significantly higher on coated substrate than on uncoated substrate; the same trend was found for the promotion of APL activity by the osteoblasts and Ca deposition by the osteoblasts; and 2) total proteins synthesized by the osteoblasts (TPSO) were greater when cultured on the uncoated substrates, although not significantly so, compared to the coated ones; and the trend in the collagen synthesis results was the same as found for the TPSO results $[40,60]$. These results suggest that the coated alloy has good potential to regenerate bone if used in implants.

Using a patented method, which is described as "transonic particle acceleration deposition process" (Spire Biomedical, Inc., Bedford, MA, USA) with pure (99.9\%) Mg substrate, 1) the nanoHA coating positively mediated $\mathrm{Mg}$ degradation both in phosphate buffered saline (PBS) and revised SBF solutions; and 2) significantly fewer rat bone marrow stromal cells adhered to both coated and uncoated specimens, in comparison to the case for the control (polystyrene cell culture plates) [1]. Each of these results points to the coated $\mathrm{Mg}$ specimen having improved properties.

\subsection{General Trends in Results}

Across the combination of deposition method, deposition variables (for a given deposition method), and substrate (Table 2), the summaries of results presented above show that while the thickness and some 
other characteristics of an nanoHA coating depended on deposition method (Table 3), the coating was consistent in significantly enhancing corrosion resistance and in vitro biocompatibility, compared to an uncoated substrate.

Table 2. Summary of process variables and typical values of variables in five nanoHA coating deposition methods.

\begin{tabular}{|c|c|}
\hline Process variables & Typical values or range of values \\
\hline \multicolumn{2}{|l|}{ ELECTROPHORETIC DEPOSITION } \\
\hline Concentration of nanoHA particles in the suspension & 10,20 \\
\hline Concentration of carbon black powder in the suspension $\left(\mathrm{g} \mathrm{mol}^{-1}\right)$ & $0 ; 2.5 ; 5.0 ; 10.0$ \\
\hline Ultrasonic dispersion time (min) & 10,60 \\
\hline Distance between working and counter electrodes (mm) & 10,20 \\
\hline Deposition voltage $(\mathrm{V})$ & $10-200$ \\
\hline Current density used in electrodeposition $\left(\mathrm{mA} \mathrm{cm}^{-2}\right)$ & $4-48,000$ \\
\hline Deposition time $(\mathrm{s})$ & $15-900$ \\
\hline \multicolumn{2}{|l|}{ SOL-GEL DEPOSITION } \\
\hline Post-production time (h) & $0-24$ \\
\hline Post-preparation sintering temperature $\left({ }^{\circ} \mathrm{C}\right)$ & $300-900$ \\
\hline \multicolumn{2}{|l|}{ ELECTRODEPOSITION } \\
\hline Current density $\left(\mathrm{mA} \mathrm{cm}^{-2}\right)$ & $1,10,15$ \\
\hline Deposition time (min) & 30,60 \\
\hline Agitation of solution during deposition & No; yes \\
\hline \multicolumn{2}{|l|}{ HYDROTHERMAL DEPOSITION } \\
\hline Temperature $\left({ }^{\circ} \mathrm{C}\right)$ & $80-200$ \\
\hline Time $(\mathrm{h})$ & $5-12$ \\
\hline \multicolumn{2}{|l|}{ ELECTROHYDRODYNAMIC SPRAY DEPOSITION } \\
\hline Distance between needle and substrate $(\mathrm{mm})$ & 20.0 \\
\hline Applied voltage $(\mathrm{kV})$ & $3.6-6.0$ \\
\hline Flow rate of nanHA suspension $\left(\square \mathrm{m} \mathrm{min}{ }^{-1}\right)$ & $0.5-33.0$ \\
\hline Spray time $(\mathrm{s})$ & $30-120$ \\
\hline
\end{tabular}

\section{Directions for Future Research}

From the preceding sub-section, it is seen that there are a number of important aspects of coating of nanoHA on bioalloy specimens that either have received little attention or have not been the subject of any study. These observations prompted ten suggestions for directions/topics for future research. Expositions on these suggestions are now given.

Regardless of the coating deposition method, coating characteristics are influenced by the process variables (for some, markedly so); as such, each method should be optimized. Work in this area is lacking and, hence, constitutes the first suggestion. The task is to select and justify the properties to be included in the optimization exercise. It is suggested that coating-substrate adhesion strength, residual stress in the coating, and corrosion rate of the coated specimen, determined in a suitable biosimulating medium (such as PBS, at $37^{\circ} \mathrm{C}$ ), be among these properties.

For the second suggestion, more work needs to be done on the growth kinetics of the coating on a given combination of deposition method and substrate. Results from a large number of results should then be analyzed to establish if a general growth law exists for that combination. 
Table 3. Comparison of someproperties of nanoHA coating on bioalloy substrates as a function of coating deposition method

\begin{tabular}{|c|c|c|c|c|c|}
\hline \multirow{2}{*}{ Property } & \multicolumn{3}{|c|}{ Deposition method $^{\mathrm{a}}$} & \multirow[b]{2}{*}{$\mathrm{AD}$} & \multirow[b]{2}{*}{ TPA } \\
\hline & EPD & SOL-GEL & HTP & & \\
\hline $\mathrm{Ca} / \mathrm{P}$ molar ratio & & & & & 1.6 \\
\hline Thickness (nm) & 1,000 & & $50-200$ & & 45 \\
\hline \multicolumn{6}{|c|}{ Range of nHA particle size (nm) } \\
\hline - in long axis & & & & & $50-1400$ \\
\hline - in short axis & & & & & $35-900$ \\
\hline Crystallite diameter (nm) & 76 & $35-42$ & & $17-21$ & \\
\hline Surface roughness $(\square \mathrm{m})$ & 45 & & & & \\
\hline Morphology & Crystalline & & & & \\
\hline Crystallinity (\%) & 12 & & & & \\
\hline Hardness (GPa) & & 1.2 & & & \\
\hline Adhesive strength $(\mathrm{MPa})$ & $11-41$ & $28-55$ & & & \\
\hline
\end{tabular}

aEPD: electrophoretic deposition; HTP: hydrothermal process; AD; aerosol deposition; TPA: transonic particle acceleration deposition.

Regardless of the anticipated biomedical application, there are a number of desirable properties of the coating and of the coated specimen that have not been reported in the literature. Among these are fracture toughness of the coating $\left(\mathrm{K}_{\mathrm{IC}}\right)$, resistance to localized indentation (hardness) of the coating $(\mathrm{HN})$, elastic modulus of the coating $(\mathrm{E})$, residual stress in the coating $\left(\sigma_{\mathrm{r}}\right)$ scratch hardness of the coating (HS), corrosion fatigue life of the coated specimen $(\mathrm{CF})$, steady-state corrosion fatigue crack propagation rate of the coated specimen (CFCP), wear rate of the coated specimen (WR), and corrosion adhesion (CAD) properties of the coating-substrate system. The third suggestion is that all of these properties should be determined using well-established methods; for example, compact tension specimen and ASTM E399 ( $\mathrm{K}_{\mathrm{IC}}$ ); nanoindentation (HN and E) [61]; and nanoindentation [62], neutron diffraction [63], and Raman piezo-spectroscopy [64] $\left(\sigma_{\mathrm{r}}\right)$. Note that HN, E, and $\sigma_{\mathrm{r}}$ should each be determined not only on the coating but through the thickness of the coating (that is, spatial variation of the property). HS should be determined using either the appropriate standard, such as ASTM G171, or a nanoindenter [65]. CF, CFCP, and CAD should each be determined in a test medium whose combination of solution, solution temperature, and frequency is appropriate to the intended biomedical application, such as SBF solution, $37^{\circ} \mathrm{C}$, and $2 \mathrm{~Hz}$ for TJRs. In addition, in the CAD tests, morphological details of the coatingsubstrate interface should be obtained after a specified number of loading cycles, especially after fracture. WR should be determined using a suitable tester, such as a pin-on-disc tester, with the pin material, applied load, and rotational speed all being clinically relevant. For each of the aforementioned properties, determination should be carried out for various combinations of coating deposition method and substrate material. Additional work in this field should concentrate on the influence of coating deposition process parameters on given properties. Results from this body of work should allow discussion of, for example, coating deposition method-versus-property relationships.

To date, study of corrosion mechanism has been conducted only on a few systems, namely, sol-gelcoated MgAZ91 alloy [29] and pulse electrodeposited-coated AZ31 Mg alloy specimens [56,57]. Clearly, more studies are needed on this issue. These studies, which constitute the fourth suggestion, should focus on, for example, 1) influence of a given coating deposition method parameter on corrosion mechanism, for a given combination of deposition method and bioalloy; and 2) similarities and differences in corrosion mechanisms for different coating deposition methods, for a given bioalloy, and for different bioalloys, for a given deposition method. In this work, experimentally-obtained EIS results (both Nyquist and Bode plots) together with counterpart results generated from computations involving appropriate equivalent electrical circuits should be utilized.

To date, the preponderance of studies has been carried out using Ti-6Al-4V, AZ31 Mg, and AZ91 Mg alloy specimens. For orthopaedic applications, research results show that there are other alloys that have many advantages over Ti-6Al-4V, examples being 1) wrought Ti-13Zr-13Nb: (i) its modulus of elasticity is $45 \%$ lower and, as such, has lower potential for stress shielding and, hence, for ensuing 
osteolysis [66]; and (ii) having no Al, it has no potential for involvement in the etiology of Alzheimer's disease [67,68]; 2) porous Ti-(4-10) Mo alloys [69], and 3) porous Co-Cr alloy: its modulus of elasticity is $55 \%$ lower [70]. For the scaffold of a bioabsorbable coronary artery stent, new Mg-based alloys, such as wrought Mg-Nd-Sr-Zr, Mg-Gd-Nd-Zn-Zr, and Fe-35Mn alloys, powder-metallurgy Fe-Au and Fe-Ag alloys, and highly-porous Mg-Y and Mg-Y-Zn-Ca-Mn alloys are being evaluated [71-74]. New alloys that show good potential for applications as both bioresorbable TJRs and coronary artery stent scaffolds include $\mathrm{Mg}-0.63 \mathrm{Ca}$ and $\mathrm{Mg}-0.89 \mathrm{Ca}$ [75]. As the fifth suggestion, studies should be conducted on deposition of nanoHA on the substrate of each of these new alloys and the full panoply of characterization tests of the coating and of the coated bioalloy specimen should be performed.

There is a growing body of literature on methods of modifying the surface of a bioalloy to improve a number of its properties. Examples are laser surface melting to improve corrosion characteristics of AM60B Mg alloy [76], double-sided laser shock peening of 316L stainless steel to increase its fatigue life [77], and high-energy electro-pulsing treatment of Ti-6Al-4V alloy to enhance its corrosion resistance [78]. As the sixth suggestion, studies should be conducted on deposition of nanoHA on the substrate of each of these surface-modified alloys and characterization of the coating and of the coated bioalloy specimen.

Apart from the deposition methods discussed in the present review, there are others that have been used to deposit nanoHA coating on bioalloy substrates that had undergone surface modification or which had a nanostructured coating, other than HA, on them. Examples of such methods are electrodeposition in the presence of a static magnetic field [79] and planetary ball milling [80]. As the seventh suggestion, each of these methods should be explored for use in the nanoHA-plain biolloy specimen system.

Results (serial angiographic and intravascular ultrasound analyses) obtained from 65 patients with coronary artery disease in whom a bioresorbable $\mathrm{Mg}$ alloy stent was implanted and followed for up to 28 mo (the PROGRESS-AMS prospective, multicenter clinical trial) revealed ISR (mean incidence of $\sim 25 \%$ at follow-up > 12 mo) [81]. It was suggested that the main mechanisms for these events were early recoil (negative remodeling of the artery area) (at follow-up of $4 \mathrm{mo}$ ) and modest neointimal formation [81]. Thus, in the next generation of bioresorbable $\mathrm{Mg}$ alloy stents, these shortcomings were addressed with the introduction of a bioresorbable drug-eluting Mg alloy stent (DREAMS-2G device), in which the entire surface of the scaffold ( $\mathrm{Mg}$ alloy) is coated with a layer of a biodegradable polymer, poly(L-lactic acid), in which a drug, sirolimus, is embedded. Results, at 6 months follow-up, of a prospective, multicenter, non-randomized first-in-man trial involving 123 patients implanted with this type of stent (BIOSOLVE-II Trial) were encouraging; specifically, favorable clinical outcomes, such as low mean neointimal area, were reported [82]. Thus, it appears that there is a strong case for adding this type of stent to the collection of modalities for surgical treatment of coronary artery disease [9]. Hence, within the context of the present review, the focus of the eighth suggestion is development of methods of depositing a nanoHA coating on the $\mathrm{Mg}$ alloy scaffold that will remain intact and stable after a drugcontaining bioresorbable polymer layer is added.

A probable life-limiting phenomenon for a nanoHA-coated coronary artery stent is failure (such as debonding) at the nanoHA coating-Mg alloy scaffold interface (in a bioresorbable non-drug-eluting $\mathrm{Mg}$ stent) or at that interface and/or the nanoHA coating-bioresorbable polymer layer interface (in a bioresorbable drug-eluting stent). As the ninth suggestion, both experimental and computational studies should be conducted to characterize the respective interface(s) and to determine factors that influence each of these characteristics.

The ultimate in vitro test of the suitability of a deposition method for biomedical implants is the use of the method on full-scale implants, such as the femoral stem of a THJR or a coronary artery stent, and evaluating the construct by performing, for example, fatigue tests (for example, stress amplitudeversus-number of cycles to fracture plots) and bioactivity tests (for example, responses to a human osteoblast-like cell line (MG-63) on coated and uncoated implants). The tenth suggestion is that these tests be performed. Upon completion of these tests and provided satisfactory results are obtained, the nanoHA-coated implants would be evaluated further; first, in appropriate small-animal models (for example, in skeletally-mature, adult New Zealand white rabbits for potential orthopaedic applications) and, then, in appropriate large-animal models (for example, in Dorset sheep for the aforementioned applications). 


\section{Summary}

The most salient points made in this review are:

- The sol-gel method, a chemical synthesis (or precipitation) method, and a hydrothermal method are among those used to synthesize nanoHA powder, with the first-named being very popular. Typical characteristics of the powder include mean thickness and morphology of the particles being $\sim 30 \mathrm{~nm}$ and ellipse-shaped when a sol-gel method was used and polygonal-shaped when a hydrothermal method was used.

- A large number of methods, such as electrophoretic deposition, sol-gel deposition, aerosol deposition, and radiofrequency magnetron sputtering, have been used to deposit nanoHA coating on substrates of alloys that are used in a number of biomedical applications; in particular, Ti-6Al-4V alloy (used in hip implants) and $\mathrm{Mg}$ alloy (used for the scaffold of fully bioresorbable coronary artery stents). Various properties/characteristics of the coating, such as thickness and morphology, and of the coated specimen, such as adhesive strength, corrosion rate, and in vitro biocompatibility performance, have been determined. For a given coating deposition process, most of the determined properties are strongly influenced by the process variables. By and large, a given property of a nanoHA-coated bioalloy specimen, especially corrosion resistance and in vitro biocompatibility, is significantly better than that of its uncoated counterpart.

- Shortcomings of the extant literature suggest directions for future research and expositions on ten such suggestions are given. Among these are determination of the optimal values of process variables for a given coating deposition method; determination of a wide array of properties of the coating, such as fracture toughness, and of the coated specimen, such as steady-state fatigue crack propagation rate; and development of methods of depositing nanoHA coating on the scaffold of a bioresorbable drug-eluting Mg coronary artery stent.

\section{References}

1. Iskandar ME, Aslani A, Liu H. The effects of nanostructured hydroxyapatite coating on the iodegradation and cytocompatibility of magnesium implants. J Biomed Mater Res A 2013; 101: 2340-2354.

2. Dorozhkin S. Nanodimensional and nanocrystalline apatites and other calcium orthophosphates in biomedical engineering, biology and medicine. Materials 2009; 2: 1975-2045.

3. Gomez-Vega JM, Saiz E, Tomsia AP, Marshall GW, Marshall SJ. Bioactive glass coatings with hydroxyapatite and Bioglass ${ }^{\circledR}$ particles on Ti-based implants. 1. Processing. Biomaterials 2000; 21: 105-111.

4. Ducheyne P, Hench LL, Kagan II A, Martens M, Bursens A, Muiler JC. Effect of hydroapatite impregnation on skeletal bonding of porous coated implants. J Biomed Mater Res 1980; 14: 225-237.

5. Tampieri A, Celotti G, Sprio S, Mingazzini C. Characteristics of synthetic hydroxyapatites and attempt to improve their thermal stability. Mater Chem Phys 2000; 64: 54-61.

6. Daines BK, Dennis DA, Amann S, Infection prevention in total knee arthroplasty. J Amer Acad Orthop Surg 2015; 23: 356-364.

7. Lewis G. Properties of antibiotic-loaded acrylic bone cements for use in cemented arthroplasties: a state-of-the art review. J Biomed Mater Res Part B: Appl Biomater 2009; 89: 558-574.

8. Stanton T. Study points to savings with infection-screening program before TJR. American Academy of Orthopaedic Surgeons November 2010; Available from: http://www.aaos.org/news/aaosnow/mar10/clinical10.asp.

9. Lewis G. Reduction in the corrosion rate of magnesium and magnesium alloy specimens and implications for plain fully bioresorbable coronary artery stents: a review. World J Eng Technol 2016; 4: 572-592.

10. Berglund IS, Brar HS, Dlgova N, Acharya AP, Keselowsky M, Sarntinoranont M, Manuel MV. Synthesis and characterization of Mg-Ca-Sr alloys for biodegradable orthopaedic implant applications. J Biomed Mater Res B Part B: Appl Biomater 2012; 100: 1524-1534

11. Anitha P, Pandya HM. Comprehensive review of preparation methodologies of nano hydroxyapatite. J Environ Nanotechnol 2013; 3: 101-121.

12. Sadat-Shojai M, Khorasani MT, Dinpanah-Khoshdargi E, Jamshidi A. Synthesis methods for nanosized hydroxyapatite with diverse structures. Acta Biomateriala 2013; 9: 7591-7621. 
13. Webster TJ, Ergun C, Doremus RH. Siegel RW, Bizio R. Enhanced functions of osteoblasts on nanophase ceramics. Biomater 2000; 21: 1803-1810.

14. Liu H, Wenping J, Ajay M. Novel nanostructured hydroxyapatite coating for dental and orthopedic implants. JOM 2009; 61.9: 67-69.

15. Razavi M, Fathi M, Savabi O, Vashaee D, Tayebi L. In vivo assessments of bioabsorbable AZ91 magnesium implants coated with nanostructured fluoridated hydroxyapatite by MAO/EPD technique for biomedical applications. Mater Sci Eng C 2015; 48: 21-27.

16. Johnson I, Khalid A, Huinan L. Nanostructured hydroxyapatite/poly (lactic-co-glycolic acid) composite coating for controlling magnesium degradation in simulated body fluid. Nanotechnology 2013; 24: 375103.

17. Rojaee R, Fathi MH, Raeissi K. Electrophoretic deposition of nanostructured hydroxyapatite coating on AZ91 magnesium alloy implants with different surface treatments. Appl Surf Sci 2013; 285: 664-673.

18. Xiong Y, Lu C, Wang C, Song R. Degradation behavior of n-MAO/EPD bio-ceramic composite coatings on magnesium alloy in simulated body fluid. J Alloys Compd 2015; 625: 258-265.

19. Anawati HA, Ono S. Enhanced uniformity of apatite coating on a PEO film formed on AZ31 Mg alloy by an alkali pretreatment. Surface \& Coatings 2015;272: 182-189.

20. Lin B, Zhong C, Zheng C, Cao L, Wang D, Wang L, Liang J, Cao B. Preparation and characterization of dopamine-induced biomimetic hydroxyapatite coatings on the AZ31 magnesium alloy. Surface \& Coatings Technology 2015;281: 82-88.

21. Diez M, Kang M-H, Kim S-M, Kim H-E, Song J. Hydroxyapatite (HA)poly (L-lactic acid) (PLLA) dual coating on magnesium alloy under deformation for biomedical applications. J Mater Sci: Mater Med 2016; 27: 34-42.

22. Feng B, Chu X, Chen J, Wang J, Lu X, Weng J. Hydroxyapatite coating on titanium surface with titania nanotube layer and its bond strength to substrate. J Porous Mater 2010; 17: 453-458.

23. Kwok CT, Wong PK, Cheng FT, Man HC. Characterization and corrosion behavior of hydroxyapatite coatings on Ti6A14V fabricated by electrophoretic deposition. Appl Surf Sci 2009; 255: 6736-6744.

24. Farnoush H, Mohandesi JA, Fatmesari DH, Moztarzadeh F. Modification of electrophoretically deposited nanohydroxyapatite coatings by wire brushing on Ti-6Al-4V substrates. Ceram Int 2012; 38: 4885-4893.

25. Farrokhi-Rad M, Kuche Loghmani S, Shahrabi T, Khanmohammadi S. Electrophoretic deposition of hydroxyapatite nanostructured coatings with controlled porosity. J Eur Ceram Soc 2014; 34: 97-106.

26. Mathew D, Garima B, Qi W, Linlin S, Batur E, Manisavagam G, Thomas JW. Decreased Staphylococcus aureus and increased osteoblast density on nanostructured electrophoretic-deposited hydroxyapatite on titanium without the use of pharmaceuticals. Int J Nanomedicine 2014; 9: 1775-1781.

27. Rojaee R, Fathi M, Raeissi K. Comparing nanostructured hydroxyapatite coating on AZ91 alloy samples via Sol-gel and electrophoretic deposition for biomedical applications. IEEE Trans Nanobioscience 2014; 13: 409-414.

28. Tian Q, Huinan L. Electrophoretic deposition and characterization of nanocomposites and nanoparticles on magnesium substrates. Nanotechnology 2015; 26 (17): 175102 (6 pp.).

29. Rojaee R, Fathi MH, Raeissi K. Controlling the degradation rate of AZ91 magnesium alloy via sol-gel derived nanostructured hydroxyapatite coating. Mater Sci Eng C 2013; 33: 3817-3825.

30. Vijayalakshmi U, Prabakaran K, Rajeswari S. Preparation and characterization of sol-gel hydroxyapatite and its electrochemical evaluation for biomedical applications. J Biomed Mater Res A 2008; 87: 739-749.

31. Byung-Dong H, Dong-Soo P, Jong-Jin C, Jungho R, Woon-Ha Y, Ki-Hoon K, Chan P, Hyoun-Ee K. Dense nanostructured hydroxyapatite coating on titanium by aerosol deposition. J Am Ceram Soc 2009; 92: 683-687.

32. Surmeneva MA, Surmenev RA. Microstructure characterization and corrosion behavior of a nanohydroxyapatite coating deposited on AZ31 magnesium alloy using radio frequency magnetron sputtering. Vacuum 2015;117: 60-62.

33. Zakaria SM, Sharif Zein SH, Othman MR, Yang F, Jansen JA. Nanophase hydroxyapatite as a biomaterial in advanced hard tissue engineering: a review. Tissue Engineering Part B: Reviews 2013; 19:431-441.

34. Wei M, Ruys AJ, Milthorpe BK, Sorrell CC. Precipitation of hydroxyapatite nanoparticles: effects of precipitation method on electrophoretic deposition. J Mater Sci: Mater Med 2005;16:319-24.

35. Chen F, Wang ZC, Lin CJ. Preparation and characterization of nano-size hydroxyapatite particles and hydroxyapatite/chitosan nano-composite for use in biomedical materials. Mater Lett 2002; 57: 858-861.

36. Fathi, M H, Hanifi A. Sol-gel derived nanostructure hydroxyapatite powder and coating: aging time optimisation. Adv Appl Ceram 2009; 108: 363-368. 
37. Corni I, Ryan MP, Boccaccini AR. Electrophoretic deposition: from traditional ceramics to nanotechnology. J Eur Ceram Soc 2008; 28: 1553-1567.

38. Li X, Huang J, Ahmad Z, Edirisinghe M. Electrodynamic coating of metal with nano-sized hydroxyapatite. BioMed Mater Eng 2007; 17: 335-346.

39. Koji K, Yoshimura M. Stoichiometric apatite fine single crystals by hydrothermal synthesis. Phosphorus Research Bulletin 1991; 1: 15-20.

40. Sato M, Sambito MA, Aslani A, Kalkhoran NM, Slamovich EB, Webster TJ. Increased osteoblast functions on undoped and yttrium-doped nanocrystalline hydroxyapatite coatings on titanium. Biomaterials 2006; 27: 23582369 .

41. Veljović DJ, Jokić Petrović BR, Palcevskis E, Dindune A, Mihailescu IN, Janaćković DJ. Processing of dense nanostructured HAP ceramics by sintering and hot pressing. Ceram Int 2009; 35: 1407-1413.

42. Chen F, Lam WM, Lin CJ, Qiu GX, Wu ZH, Luk KDK, Lu WW. Biocompatibility of electrophoretical deposition of nanostructured hydroxyapatite coating on roughen titanium surface: in vitro evaluation using mesenchymal stem cells. J Biomed Mater Res B Appl Biomater 2007; 82: 183-191.

43. Mihailović M, Aleksandra P, Zvonko G, Dorde V, Dorde J. Electrophoretically deposited nanosized hydroxyapatite coatings on 316lvm stainless steel for orthopaedic implants. Chem Ind Chem Eng Q 2011; 17: 4552 .

44. Seyfoori A, Mirdamadah M, Mehrjoo M, Khavandi A. In vitro measurements of micro-arc oxidized ceramic films on AZ 31 magnesium implant: degradation and cell-surface response. Prog Nat Sci Mater Int 2013; 23: 425-433

45. Li W, Guan S, Hu J, Chen S, Wang L, Zhu S. Preparation and in vitro degradation of the composite coating with high adhesion strength on biodegradable Mg-Zn-Ca alloy. Mater Charact 2011;62:1158-1165.

46. Zhang Z, Dunn MF, Xiao TD, Tomsia AP, Saiz E. Nanostructured hydroxyapatite coatings for improved adhesion and corrosion resistance for medical implants. MRS Mater Res Sym Proc 2002; 703: 290-296.

47. Shadanbaz S, Dias GJ. Calcium phosphate coatings on magnesium alloys for biomedical applications: a review. Acta Biomaterialia 2012; 8: 20-30.

48. Madved J, Mrvar P, Voncina M, Oxidation resistance of AM60, AM50, AE42 and AZ91 magnesium alloys, in: Czerwinski F (Ed.), Magnesium Alloys - Corrosion and Surface Treatments, chapter 2; InTechOpen d. o. o., Rijeka, Croatia; 2011.

49. Orazem ME, Tribollet B. Electrochemical Impedance Spectroscopy. John Wiley \& Sons, Inc., Hoboken, New Jersey, 2008.

50. Singh S, Meena VK, Sharma M, Singh H. Preparation and coating of nano-ceramic on orthopaedic implant material using electrostatic spray deposition. Materials \& Design 2015; 88: 278-286.

51. Hu R, L C-J, Shi H-Y. A novel ordered nano hydroxyapatite coating electrochemically deposited on titanium substrate. J Biomed Mater Res A 2007; 80A: 687-692.

52. Narayanan R, Kim SY, Kwon TY, Kim KH. Nanocrystalline hydroxyapatite coatings from ultrasonated electrolyte: preparation, characterization, and osteoblast responses. J Biomed Mater Res A 2008; 87: 1053-1060.

53. Xiong, J, Yuncang L, Peter DH, Cui'E W. Nanohydroxyapatite coating on a titanium-niobium alloy by a hydrothermal process. Acta Biomaterialia 2010; 6: 1584-1590.

54. Hahn BD, Lee JM, Park DS, Choi JJ, Ryu J, Yoon WH, Choi JH, Lee BK, Kim JW, Kim HE, Kim SG. Enhanced bioactivity and biocompatibility of nanostructured hydroxyapatite coating by hydrothermal annealing. Thin Solid Films 2011; 519: 8085-8090.

55. International Standards Organization (ISO). ISO 13779-2. Implants for surgery-Hydroxyapatite-Part 2: Coatings of hydroxyapatite; ISO, Geneva, Switzerland; 2000.

56. Saremi M, Mohajernia S, Hejazi S. Controlling the degradation rate of AZ31 Magnesium alloy and purity of nano-hydroxyapatite coating by pulse electrodeposition. Mater Lett 2014; 129: 111-113.

57. Mohajernia S, Hejazi S, Eslami A, Saremi M. Modified nanostructured hydroxyapatite coating to control the degradation of magnesium alloy AZ31 in simulated body fluid. Surf Coat Technol 2015; 263: 54-60.

58. Leeflang MA, Dzwonczyk JS, Zhou J, Duszczyk. Long-term biodegradation and associated hydrogen evolution of duplex-structured Mg-Li-Al-(RE) alloys and their mechanical properties. Mater Sci Eng B 2011; 176: 1741-1745.

59. Huang Y, Song L, Huang T, Liu X, Xiao Y, Wu Y, Wu F, Gu Z. Characterization and formation mechanism of nano-structured hydroxyapatite coatings deposited by the liquid precursor plasma spraying process. Biomed Mater 2010; 5: 054113. 
60. Sato M, Aslani A, Sambito MA, Kalkhoran NM, Slamovich EB, Webster TJ. Nanocrystalline hydroxyapatite/titania coatings on titanium improves osteoblast adhesion. J Biomed Mater Res A 2008; 84: 265272 .

61. Lewis G, Nyman J. Nanomechanical properties of mineralized hard tissues: state-of-the art review. J Biomed Mater Res Part B: Appl Biomater 2008;87: 286-301.

62. Zhu LN, Xu BS, Wang HD, Wang CB. Measurement of residual stresses using nanoindentation method. Crit Rev Solid State Mater Sci 2015; 40: 77-89.

63. Ahmed R, Faisal NH, Paradowska AM, Fitzpatrick ME, Khor KA. Neutron diffraction residual strain measurements in nanostructured hydroxyapatite coatings for orthopaedic implants. J Mech Behav Biomed Mater 2011; 4: 2043-2054.

64. Sergo V, Sbaizero O, Clarke DR. Mechanical and chemical consequences of the residual in plasma sprayed hydroxyapatite coatings. Biomater 1997; 18: 477-482.

65. Karimzadeh A, Ayatollahi MR. Investigation of mechanical and tribological properties of bone cement by nanoindentation and nano-scratch experiments. Polym Test 2012;31:828-833.

66. Niinomi M, Nakai M, Hieda J. Development of new metallic alloys for biomedical applications. Acta Biomaterialia 2012; 8: 3888-3903.

67. Davidson JA, Mishra AK, Kovacs P, Poggie RA. New surface hardened low-modules, corrosion-resistant Ti13Nb-13Zr alloy for total hip arthroplasty. Biomed Mater Eng 1994; 4: 231-243.

68. Lugowski SJ, Smith DC, McHugh AD, Loon V. Release of metal ions from dental implant materials in vivo: determination of Al, Co, Cr, Mo, Ni, V and Ti in organ tissue. J Biomed Mater Res 1991; 25: 1443-1458.

69. Xie F, He X, Lv Y, Wu M, He X, Qu X. Selective laser sintered porous Ti-(4-10) Mo alloys for biomedical applications: Structural characteristics, mechanical properties and corrosion behaviour. Corros Sci 2015; 95: 117124 .

70. Lewis G. Properties of open-cell porous metals and alloys for orthopaedic applications. J Mater Sci: Mater Med 2013; 24: 2293-2325.

71. Zhang XB, Zhang Y, Chen K, Ba ZX, Wang ZZ, Wang Q. Microstructure, mechanical and corrosion properties of Mg-Nd-Zn-Sr-Zr alloy as a biodegradable material. Mater Sci Technol 2015; 31: 866-873.

72. Sing NB, Mostavan A, Hamzah E, Mantovani D, Hermawan H. Degradation behavior of biodegradable Fe35Mn alloy stents. J Biomed Mater Res B Appl Biomater 2015; 103: 572-577.

73. Huang T, Cheng J, Bian D, Zheng Y. Fe-Au and $\mathrm{Fe}-\mathrm{Ag}$ composites as candidates for biodegradable stent materials. J Biomed Mater Res B Appl Biomater 2016;104:225-240.

74. Morgenthal I, Andersen O, Kostmann C, Stephani G, Studnitzky T, Witte, F, Kieback B. Highly porous magnesium alloy structures and their properties regarding degradable implant application. Adv Eng Mater 2014; 16: 309-318.

75. Mareci D, Bolat G, Izquierdo J, Crimu C, Munteanu C, Antoniac I, Souto RM. Electrochemical characteristics of bioresorbable binary $\mathrm{MgCa}$ alloys in Ringer's solution: revealing the impact of local $\mathrm{pH}$ distributions during invitro dissolution. Mater Sci Eng C 2015; 60: 402-410.

76. Liu C, Liang J, Zhou J, Wang L, Li Q. Effect of laser surface melting on microstructure and corrosion characteristics of AM60B magnesium alloy. Appl Surf Sci 2015; 343: 133-140.

77. Correa C, de Lara LR, Díaz M, Gil-Santos A, Porro JA, Ocaña JL. Effect of advancing direction on fatigue life of 316L stainless steel specimens treated by double-sided laser shock peening. Int J Fatigue 2015; 79: 1-9.

78. Ye X, Wang L, Zion TH, Tang G, Song G. Effects of high-energy electro-pulsing treatment on microstructure, mechanical properties and corrosion behavior of Ti-6Al-4V alloy. Mater Sci Eng C 2015; 49: 851-860.

79. Xu Q, Liu Y, Liu C, Tian A, Shi X, Dong C, Zhou Y, Zhou H. Performance of hydroxyapatite coatings electrodeposited on micro-arc oxidized magnesium alloys using a static magnetic field. RSC Adv 2015; 5: 1445814464 .

80. Yazdani A, Zakeri A. An insight into formation of nanostructured coatings on metallic substrates by planetary ball milling. Powder Technol 2015; 278:196-203.

81. Waksman R, Raimund E, Carlo DM, Jozef B, Bernard B, Franz RE, Paul E, Haude M, Horrigan M, Ilsley C, Böse D, Bonnier H, Koolen J, Lüscher TF, Weissman NJ. Early-and long-term intravascular ultrasound and angiographic findings after bioabsorbable magnesium stent implantation in human coronary arteries. JACC Cardiovasc Interv 2009; 2: 312-320. 
82. Haude M, Ince H, Abizaid A, Toelg R, Lemos PA, von Birgelen C, Christiansen EH, Wijns W, Neumann FJ, Kaiser C, Eeckhout E, Lim ST, Escaned J, Garcia HM, Waksman R. Safety and performance of the secondgeneration drug-eluting absorbable metal scaffold in patients with de-novo coronary artery lesions (BIOSOLVEII): 6 month results of a prospective, multicentre, non-randomised, first-in-man trial. Lancet 2015; 387 (10013): 31-39. 